\title{
HACKING THE SYSTEM / OPEN ACCESS
}

\author{
Abraham San Pedro Salazar
}

$\checkmark$ magazine, Medialabmadrid, LABoral, ZKM...

\begin{abstract}
Resumen
Codificación, normatividad, semiótica heterónoma, patologización/integración, mercantilización... Estas son algunas de las características/problemas (bugs o errores a hackear con nuestros exploits) del actual Sistema Arte, un espacio humano que por sus especiales características debiera estar configurado como un no lugar dinámico y líquido donde los elementos, personas y obras fueran prácticas inesperadas e incluso ininteligibles. Todo diálogo real (que está inscrito en la propia esencia del arte como 'Academia' donde practicar la 'synethesis' entre iguales) queda sepultado por la ortodoxia del discurso interno de la obra de arte. Una herencia platónica (la 'idéa' que configura el 'eidos') que nos pone ante la realidad de la centralidad del discurso encerrado, de la narración oculta (velada para los ojos del extraño) que disciplinan curadores y críticos de arte explicando cada una de las obras que ellos dictaminan son arte integrable por el sistema, o si deben ser patologizadas en el mundo no arte en caso contrario. Queda así institucionalizada una hermenéutica, un 'texto interno' y 'verdadero' que dificulta -oficialmente- el acceso a la experiencia arte al espectador/usuario. Estos saberes/poderes de la institución desplazan al usuario y al dispositivo/obra de arte hasta la marginalidad del silencio y la admisión de la una verdad ortodoxa del todo ajena a su propia experiencia con la obra. Como hacker del Sistema Arte he llevado a cabo una acción en términos semióticos, simbólicos, lingüísticos, operativos y económicos. Esta es una inversión del artefacto/dispositivo 'libro' finiquitando la centralidad del texto en el espacio del saber/poder Sistema del Arte. Eliminar toda textualidad no sólo atañe a los patrones geomentales de pensamiento (de izquierda a derecha de arriba abajo, en Occidente), sino que resulta una bomba de racimo al empoderamiento del texto sobre la obra de arte. Abriendo así la posibilidad de un libre análisis de la obra (y contexto) de arte explicito acuerdo de mutuo respeto entre usuario y obra estableciendo así un modelo abierto de cooperación. Al mismo tiempo se ha ignorado los derechos de difusión y distribución de los tenedores de derechos y se ha realizado una 'publicación pirata', pero en alta calidad. Del mismo modo, otro de los bugs a explotar ha sido la transversalidad y multidimensionalidad de las obras recogidas en la publicación, ya que, aunque es una narración 'artística' está plagada de elementos marginales ajenos al asunto del arte (publicidad, ciencia, ocio de masas...). El libro (350 páginas a todo color) está siendo impreso estos días antes de su distribución a bibliotecas públicas de todo el mundo y ya está disponible online en dos versiones, una para descarga a 300 pp. y otra interactiva enriquecida con las obras audiovisuales de la narración.
\end{abstract}

\section{Palabras clave: BUG; EXPLOIT; DIÁLOGO; TEXTO INTERNO; CURADOR}

\section{Abstract}

Coding, normativity, heteronomous semiotics, pathologization/integration, commercialization... These are some of the characteristics/problems ('bugs' or errors to hack with our 'exploits') of the current Art System, a human space that due to its special characteristics should be configured as dynamic 'no place' and also as a 'liquid' space where the elements, people and

\section{AUSART}


works were unexpected and even unintelligible practices. All real dialogue (which is inscribed in the very essence of art as 'Academy' where practicing the 'synethesis' among equals) is buried by the orthodoxy of the internal discourse of the artwork. A Platonic inheritance (the 'idéa' that configures the 'eidos') that puts us before the reality of the centrality of the closed discourse, of the hidden narration (veiled for the eyes of the stranger) that disciplines curators and art critics explaining each one of the works that they dictate are integrable art by the system, or if they should be pathologized in the non-art World in other case. It is thus institutionalized a hermeneutics, an 'internal text' and 'true' that makes it difficult -officially- the access to the art experience to the spectator/user. These knowledge/powers of the institution displace the user and the device/ artwork to the marginality of silence and the admission of an orthodox truth completely alien to their own experience with the work. As a hacker of the Art System, I have carried out an action in semiotic, symbolic, linguistic, operative and economic terms. This is an inversion of the artifact / device 'book' ending the centrality of the text in the space of knowledge / power System of Art. Eliminating all textuality not only concerns the geomentale patterns of thought (from left to right from top to bottom, in the West), but it is a cluster bomb to the empowerment of the text on the artwork. Opening thus the possibility of a free analysis of the work (and context) of art explicit agreement of mutual respect between user and work thus establishing an open model of cooperation. At the same time, rights of dissemination and distribution of rights holders have been ignored and a 'pirated publication' has been made, but in high quality. In the same way, another of the bugs to be exploited has been the transversality and multidimensionality of the works included in the publication, since although it is an 'artistic' narrative, it is full of marginal elements that are alien to the subject of art (advertising, science, leisure masses...). The book (350 pages in full color) is being printed these days before distribution to public libraries around the world and is now available online in two versions, one for download at 300pp. and another interactive enriched with the audiovisual works of the book narrative.

Keywords: BUG; EXPLOIT; DIALOGUE; INTERNAL TEXT; CURATOR

\footnotetext{
San Pedro Salazar, Abraham. 2018. "Hacking the system / Open access". AusArt 6(2): 213-231. D0I:10.1387/ausart.20334
} 


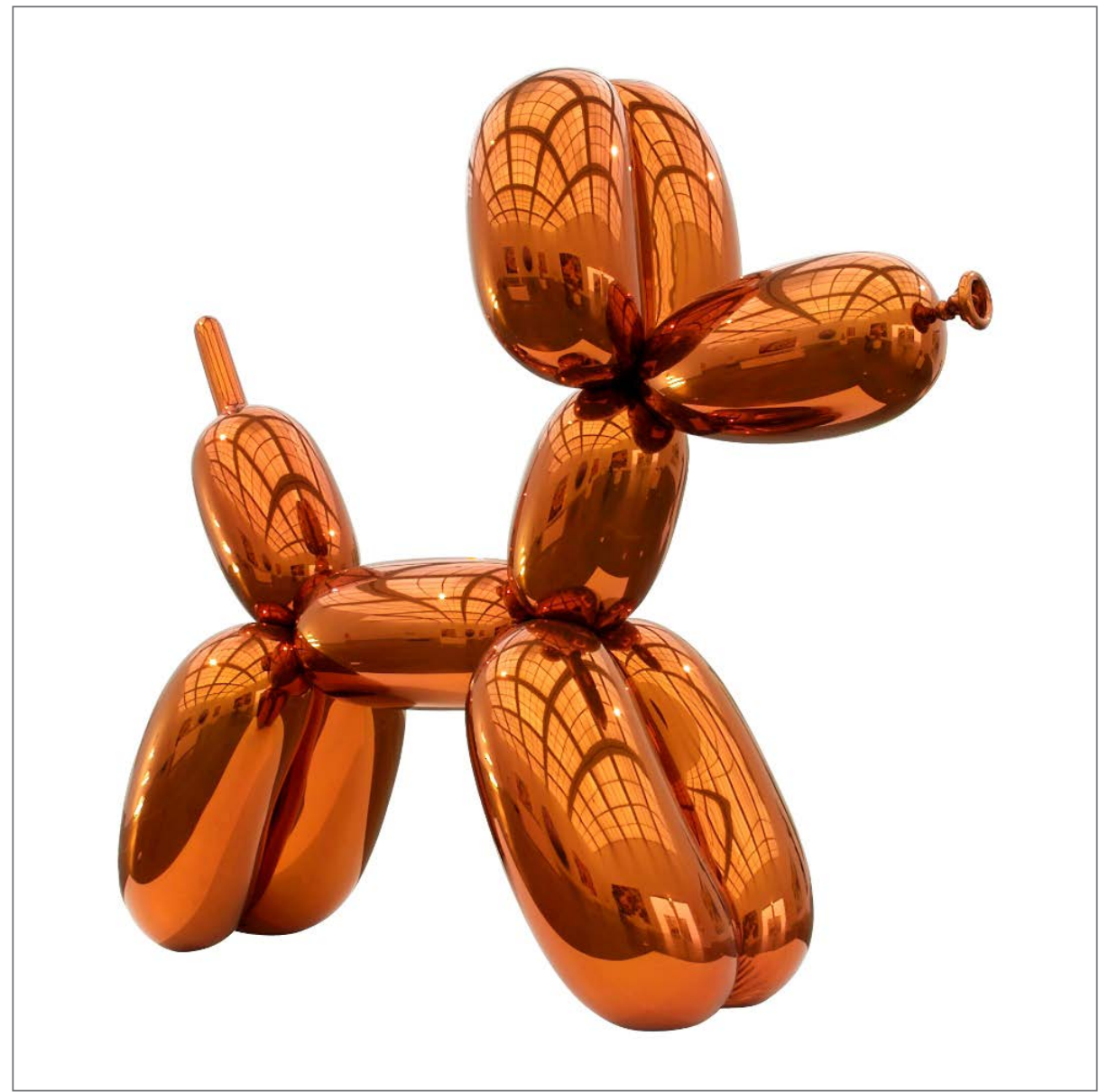

Jeff Koons, Balloon Dog (Orange), firmado y fechado 'Jeff Koons 1994-2000', acero galvanizado pulido en espejo con barniz transparente de color $(307.3$ x 363.2 x $114.3 \mathrm{~cm})$, Colección privada; Imagen: @ Jeff Koons / Saatchi

Sí, soy un delincuente. Mi delito es la curiosidad...

El manifiesto del hacker, El Mentor (1986)

A 2019, todo el que pase por aquí encontrará desplegado un Sistema Arte funcional y rampante. Hiperoperativo. Fordista. Total. Un sistema de producción seriada ${ }^{1}$ de objetos únicos (Bunz 2017). Maximalizando, al tiempo, beneficios y cobertura mediática. Transparente y veloz. Integrado en las otras redes 
de saberes/poderes que disciplinan nuestras vidas ya globalizadas, digitales, sobreexpuestas (Virilio 1991) y delgadas. 58 millones por un perro². ¿Acaso puede ir mejor? La mayoría dirá que no, que esto es ya excelente y cornucopia 4K. Sin embargo, otros hemos venido a cambiar las cosas. A enfrentarnos al arti-facto del Arte deslizándonos por entre sus rendijas e intersticios. Por zonas no transitadas y sin apenas luz. Encontraremos los bugs ${ }^{3}$, los errores de código del sistema, con nuestras herramientas ${ }^{4}$ llenas de ética y sentido de la responsabilidad colectiva.

\section{BUGS / ERRORES DEL SISTEMA}

De este gran montaje superestructural que es la cosa del arte (Sistema Arte: museos, galerías, centros de arte, becas, redes de trabajo...) hay que atender con especial atención y recelo a cuatro de sus principales actuales rasgos definitorios (que a la vez son sus bugs fatales) contra los que hemos venido a enfrentarnos de un modo u otro:

1. Codificación, pues toda obra de arte se encuentra categorizada, taxonomizad ${ }^{5}$ dentro de una tipología que la explica ya por su mera pertenencia a esta. En nuestra sociedad Occidental -hija de la llustración- los saberes están unificados y compartimentados no pudiendo dejar nada que exista fuera de estas presignificadas categorías. Todo conocimiento debe poder ser entendido dentro de la estructura genealógica de la razón y la ciencia etnocentrada por el hombre europeo y su perverso proyecto modernista. Fuera sólo está lo ininteligible, la superchería y lo marginado (lo invisible). Nosotros.

2. Semiótica heterónoma, que se encuentra en el establecimiento externo al espectador/usuario de unos códigos hermenéuticos desde los cuales leer cualquier obra o experiencia artística. Se ha impuesto un lenguaje de traducción heterónomo (fruto de una decisión históricamente consensuada por unas élites vinculadas a la Institución del Arte y, por tanto, arbitrario). Se trata de un habla con códigos interpretativos restrictivos, esto es, privados y disfuncionales con el resto de lógicas operativas en las demás esferas sociales. Este código de interpretación (Sontag [1966] 2018) tiene sentido solo circunscrito a la red del Sistema Arte, haciendo que prácticas u objetos tengan una 
significación "z" en las demás redes de poder de una sociedad (sistema económico, político, familiar...) y, sin embargo, en el sistema arte, el código particular impuesto le concede un sentido "p" desvinculado por completo de las nociones de identidad, sentido, funcionalidad o relevancia que si se aplican en el resto de esferas. Un urinario ${ }^{6}$, sin ir más lejos, muta su significación si está en la pared de un baño público, o si se encuentra en un concurso de escultura. Pobre Marcel, no ganó.

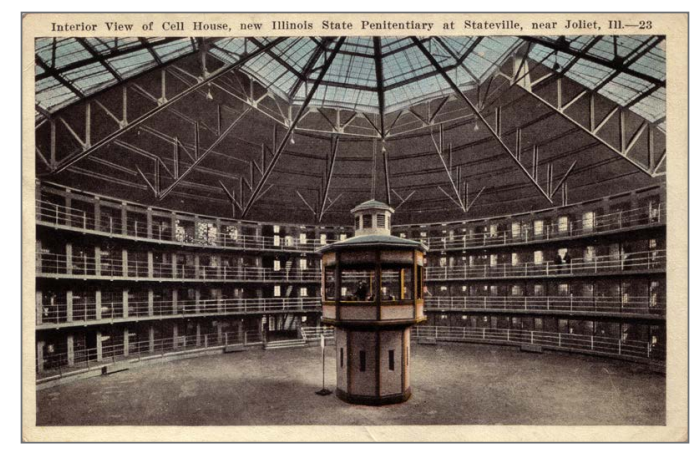

Autor desconocido, Interior View of Cell House, New Illinois Penitenciary at Stabeville, postal, impresión en color sobre cartón, c.1890; Imagen: Dominio público

3. Normatividad, pues todo lenguaje es un régimen disciplinario (Foucault [1975] 2012, 67) de control de los cuerpos y de sus interacciones entre ellos. El lenguaje del Sistema Arte regula las prácticas y procesos de los individuos dentro de su red de poder/saber (Foucault [1994] 1999, 389). Esta regulación es disciplinaria y, como tal, castiga a quien no cumple con el lenguaje obligatorio que son sus pautas y criterios, puede ser con el silencio o la marginalidad. Tal es así, que quedan fijadas (tras los sucesivos pactos) las nociones de lo 'aceptable' y lo 'no aceptable'. De lo 'válido' y lo 'inútil'. De lo 'caro' y lo 'barato'. De lo que está 'dentro' -y por tanto existe como arte- y lo que se queda 'fuera' (territorio sin nombre y sin forma que habitan desde los simios superiores ${ }^{7}$ que dibujan, los enfermos mentales y su art brut ${ }^{8}$ la pornografía explícita, o cualquier productor de contenido audiovisual que no pase el filtro de selección del sistema).

Esta normatividad implica una disciplina de castigo radical en los tipos de acciones y experiencias que los sujetos practican o están 
dispuestos a practicar al aplicar una 'distinción coercitiva' entre 'patología' y 'normalidad' en palabras de Michel Foucault. Ante un sistema que deja claro lo que sí asumirá y validará y lo que no, el creador ya está orientado a la hora de decidir qué hacer, pues una apuesta por lo extraoficial conlleva -ya de antemano- la punición de silencio y de las puertas cerradas.

4. Mercantilización, pues el Sistema Arte ha adoptado los fines y procesos del Sistema Financiero en una mutación gradual hasta llegar a la completa mimesis. Es cierto que el arte siempre ha tenido un aspecto económico, pero este estaba vinculado al valor de uso (Marx [1867] 1975) para la propia manutención del creador. Sin embargo, durante el proceso de monetarización del Sistema Arte, el valor de uso pasó a ser valor de cambio (ibíd.), dando paso a la aparición del Mercado del Arte (fetichismo de la mercancía) (ibíd.) como un perfecto espejo del mercado financiero donde se manejan productos derivados como las 'opciones call', los 'futuros' y sus 'liquidaciones por diferencia', participaciones interpuestas en 'hipotecas basura', o grano de café retenido en hangares. Especulación. La base en la cual se cimientan ambos sistemas monetarios es idéntica: orientación a la ganancia lucrativa y desvinculación de la economía productiva (en el caso del arte, desvinculación de la vida real). Tal ruptura con lo real se manifiesta en la sintomática característica del arte contemporáneo: su reproductibilidad en bucle -ya que al igual que el resto de la sociedad ha pasado de ser 'productiva' a ser 'reproductiva'- así como en su jovial tono de entretenimiento (entertainmet bussines) que lo convierte en artículo de consumo masivo en forma de actividad de ocio turística (MacCannell [1976] 2017).

El turista (el gran target de los grandes centros museísticos mundiales que ya usan logaritmos complejos ${ }^{9}$ para gestionar sus colas ingentes de turistas con prisa) es el perfecto epígono de una cultura artística determinada: inmediata, banal, intercambiable, exaltada, masificada y con olor a humanidad. El arte se ha devenido en cosa de rápido consumo y renovación constante (pronta moda). Algo telegénico y comunicable. Indiferenciado y olvidable pues en realidad solo habitará en el tiempo brevemente -lo que dura un 'click'-en las memorias de los smartphones de estos turistas. Fotografías que no se volverán a mirar tras su segundo de gloria. Así es. El arte se ha deslizado desde lo opaco a lo transparente. Del relieve a las superficies pulidas y brillantes. De la creación a la recreación. Y a lo recreativo. Claro. 


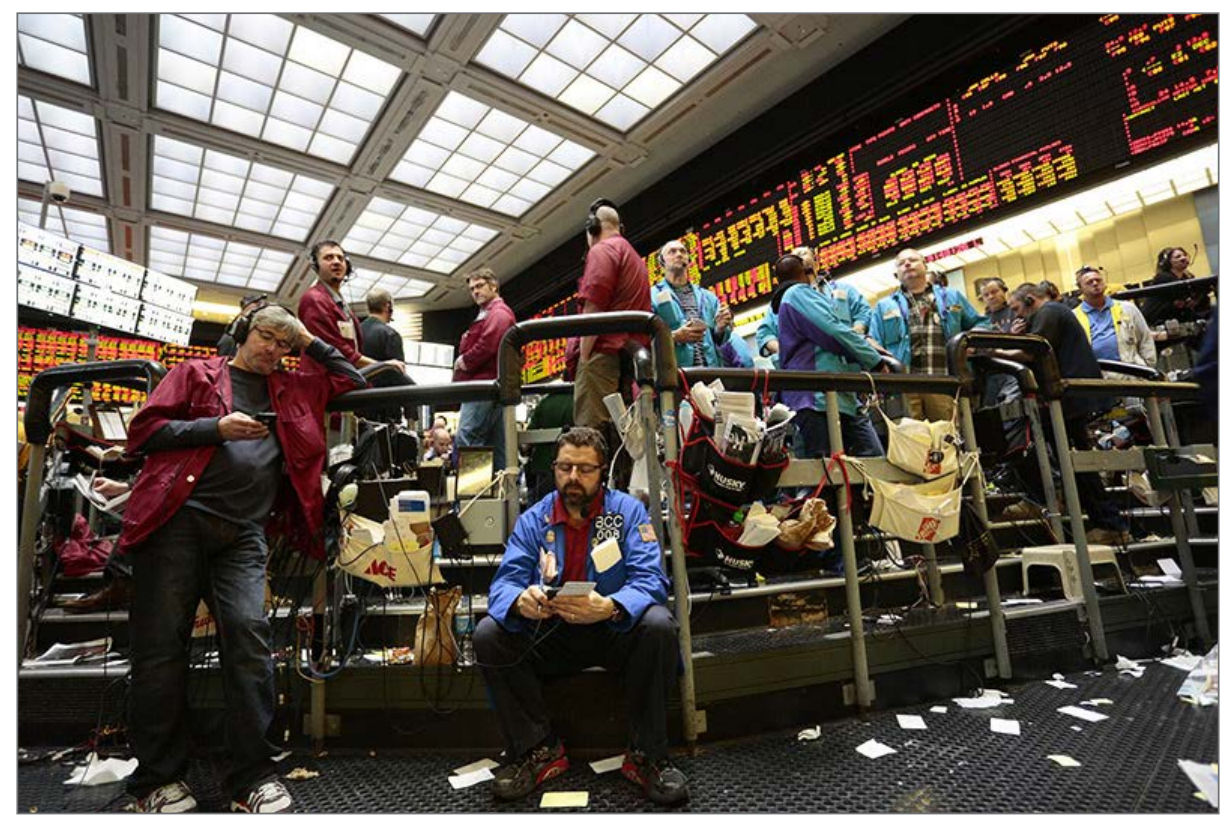

Autor desconocido, Bolsa de Chicago (Trade Exchange Floor) a la hora del cierre, 2015; Imagen: @ New York Times

\section{LA IDEA / EL TEXTO OCULTO}

Estas son sólo algunas de las características del actual Sistema Arte, un espacio humano que por sus especiales características debiera estar configurado como un no lugar dinámico (Augé 1993) y líquido (Bauman 2005) donde elementos, personas y obras desplegasen prácticas inesperadas, e incluso ininteligibles. Un territorio, que imaginaríamos poroso e incierto, dando lugar -al dejar entrar al Otro $^{10}$ (desconocido)- a un espacio de rico intercambio y dialógica mutua desde el respeto y la equiparación de los interlocutores. Un horizonte este que, curiosamente comparten Platón y lo hacker, pues el griego planteaba el arte como Academia donde practicar la synethesis entre iguales. Todo lo contrario a la medieval regla monástica de San Benito de aprendizaje unidireccional y jerarquizado del que hoy somos herederos directos. Se podría decir que tenemos una escuela monástica informatizada (Himanen2001, 96). Por el contrario, la ética hacker (ibíd., 211) entiende la red y el conocimiento como un lugar para el diálogo directo entre iguales (ibíd., 99), un espacio destinado a ser territorio de acceso universal (Suber 2013, 29). 
Cuando Platón henchido de geometría distinguía la idéa del eidos, hipotecaba, por lo menos dos mil años, la noción de todas las cosas y las del arte en particular. Si la idéa era la forma ideal pura hacia la que la existencia espiritual de algo debía tender, su proyección fenomenológica debía participar de esas mismas características ideales como horizonte de mimesis. Aunque nunca alcanzase la perfección de la idéa. Así encerró, sin sospecharlo siquiera, todo discurso de la obra de arte a una cárcel (su realidad física) de la que habría que sacarle para poder leer el texto oculto y velado por la engañosa forma ${ }^{11}$. Esta herencia maldita nos cubre todavía hoy cuando nos permitimos preguntarnos ¿Qué habrá querido manifestar el artista con esta pieza en forma de vaso medio lleno de agua? O tal vez al toparnos de bruces con un vertedero real desplegado en el Pabellón Español de la Bienal de Venecia ${ }^{12}$. Lo que pasa es que hay un mensaje interno y usted no sabe, ni puede, llegar a él.

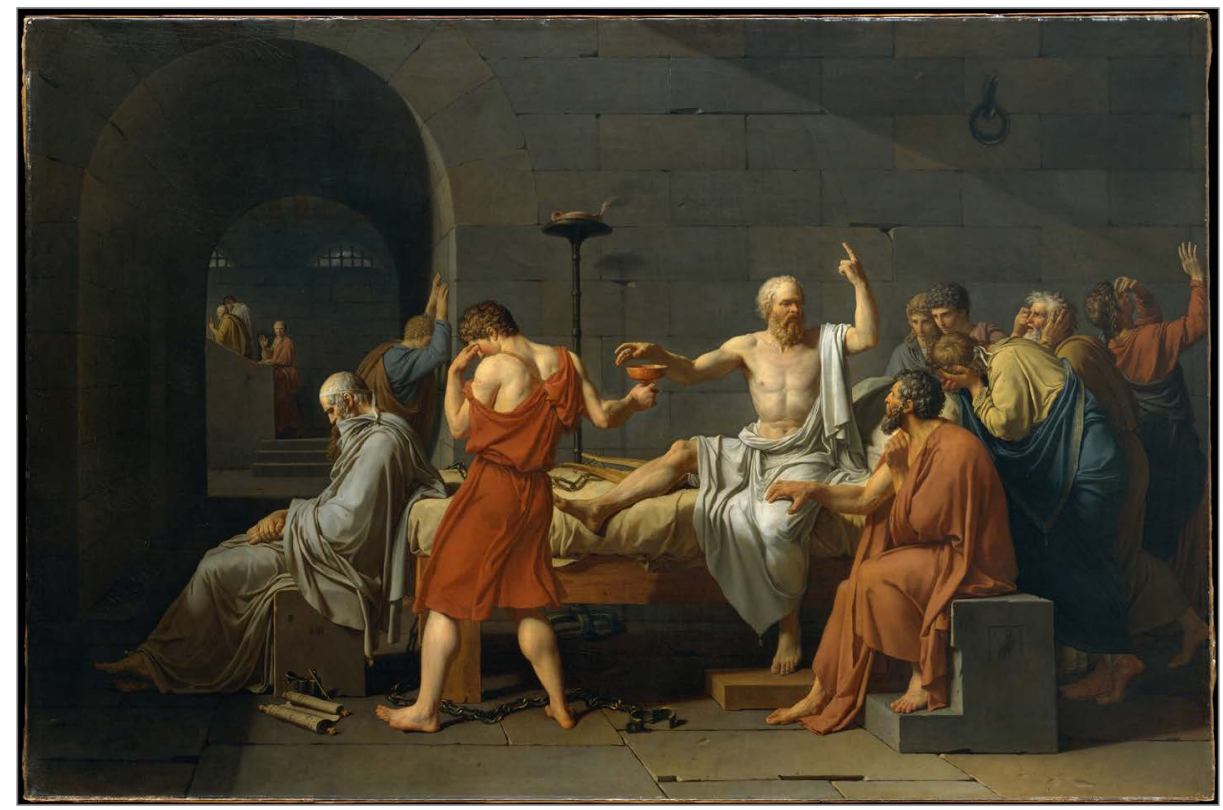

Jacques-Louis David, La Muerte de Sócrates, 1787, óleo sobre lienzo, 1,3×1,96m, Metropolitan Museum of Art, Nueva York; Imagen: MET/Dominio público.

\section{INTEGRACIÓN / PATOLOGIZACIÓN}

Nuestro sistema capitalista postindustrial ${ }^{13} \mathrm{o}$ si se quiere ultramoderno, o hipermoderno (dejando atrás la vergüenza de la hipnosis de Las Vegas [Venturi, Brown \& Izenour 1977] donde se hacían añicos los grandes relatos [Lyotard 
(1979) 2000]) llega a conceptualizarse a sí mismo incluso como capitalismo artístico (Lipovetsky \& Serroy 2015). Si. Han leído bien. Un sistema donde la industria del ocio habría pasado así a inundar y fecundar con sus estrategias fatales (Baudrillard [1983] 2000)el resto de ámbitos tecno-económicos. Surge así un sistema de valores transestéticos donde, aunque el arte inunda todas las esferas económicas dotándoles de look, punch y postverdad (Mcintrye 2018) en una constante renovación (moda, diseño industrial, videoclips,...), donde este ha perdido ya toda definición ('desdefinición') (ibíd.) que le pudiera situar como espacio de disentimiento, de sorpresa, de conflicto, de ampliación del campo de batalla. Todo sujeto está integrado en el sistema o a la

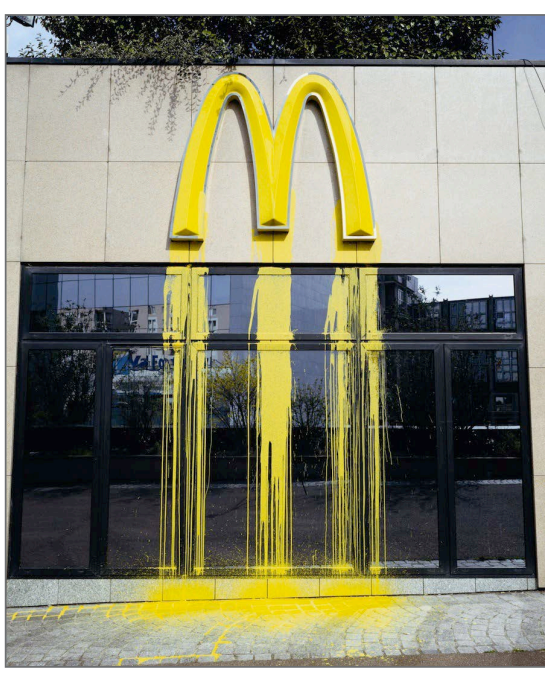

ZEVS, Liquidated McDonalds, Paris, 2002 Imagen: @ ZEVS espera de estarlo (Lucaks).

Las ex-infames Guerrilla Girls ya son parte normalizada del Sistema Arte pues tienen sus afiches bien colocados en los mejores y más trascendentales Museos de Arte Contemporáneo del mundo (Centro Georges Pompidou: planta 4, pasillo central). Banksy se subasta en forma exponencial y mediática entre Nueva York y Londres. El sistema Arte ha sabido silenciar e integrar a los disidentes del mundo de un modo plenamente eficaz y ulterior. Esto sólo puede hacernos mirar con nostalgia a los idealistas como el cordobés Equipo 57 que otrora allá por 1959 seguían contumaces con la vanguardia utópica modernista que se niega a firmar sus obras y pedía -vía manifiesto ${ }^{14}$ - una tasación idéntica por metro cuadrado de los lienzos para todos los artistas del mundo. En fin... Mucho más tarde, el -aún-grafitero anónimo francés ZEVS tiraba pintura sobre los logos de las grandes marcas en plena calle (McDonalds, British Petrolum, Chanel...), hasta que las marcas pasaron a invitarle como Host Star a sus soireés donde ahora hace Ready Painting Actions (pero indoors). Pasando por caja, of course (darling).

Tantas voces disonantes han sido víctimas de su propia simulación como acción performativa que hemos perdido la cuenta y -de paso- el sentido de lo que significa lo real. Para Jean Baudrillard (1979), lo real ya se extinguió o, al menos, está en vías inevitables de extinción, víctima de un sistema que 
ha reducido dramáticamente las posibilidades de que lo real se produzca. Así este sistema es un sistema de simulación ${ }^{15}$. Y su forma más perfecta la forma extática sobre la que parecen girar todos los nuevos formatos de presentación de las cosas. Todo es superlativo y exponencial. Todo parece fluir, emerger con la fuerza de lo definitivo superior y novísimo. Consumidor Pro. Consumidor Premium. El porno es, según Jean Baudrillard, la forma extática del sexo, hay más sexo que en el sexo, lo que allí ocurre es superlativo y demencialmente extremo, queda, por tanto, vaciado de todo contenido sexual real a manos de la fuerza centrífuga. Esta lógica de la extatización de las cosas afecta-por supuesto- al Sistema Arte. Todo sigue una misma escala de redoblamiento y espectacularidad (véase sino la autodestrucción de la obra de Banksy en plena subasta londinense $\left.{ }^{16}\right)$. Ya no basta con sacar las vergüenzas y el dinero a la burguesía, hay que destruir el objeto mismo como acción artística para poder seguir estando en el cutting edge.

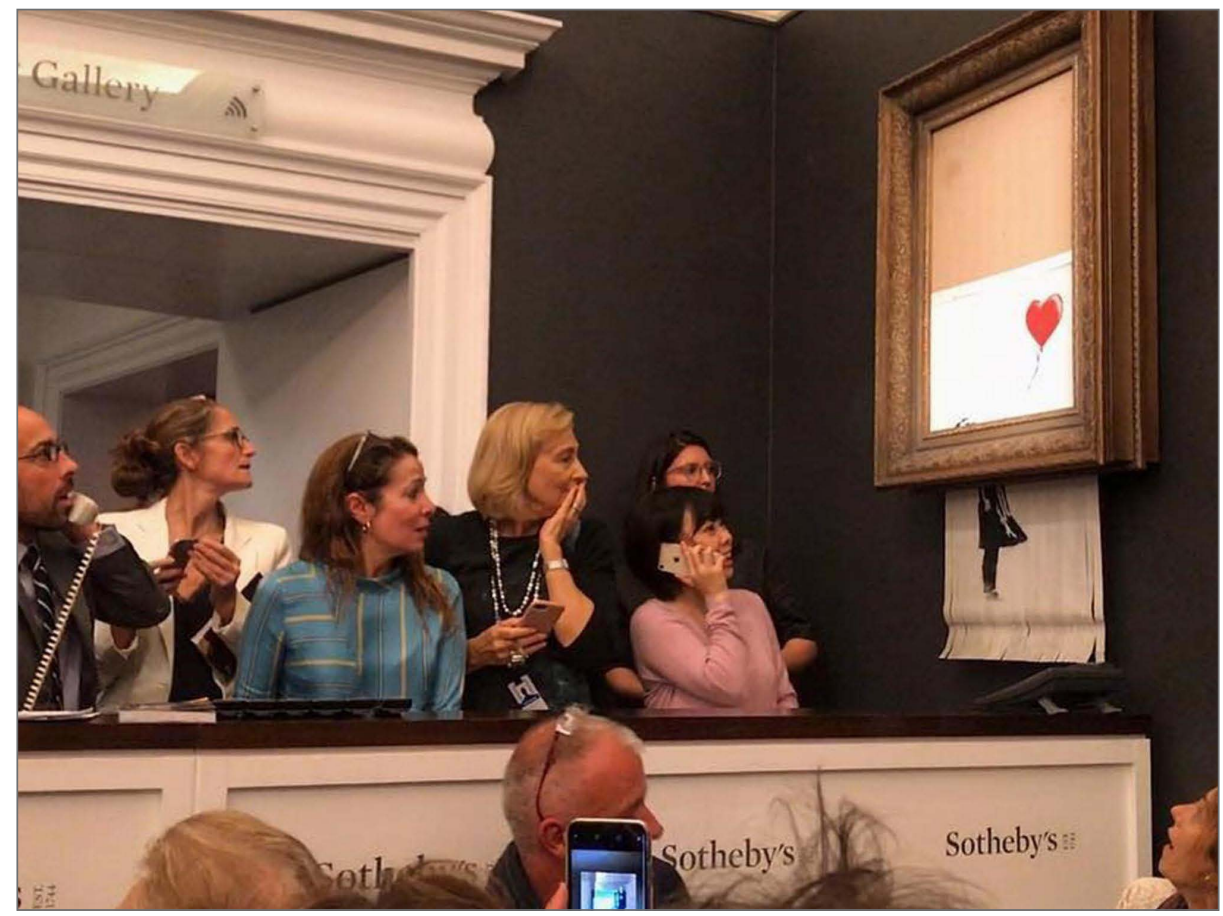

Autor desconocido, Ballon Girl de Banksy en el proceso de autodestrucción, Sala Sotheby's, 6 de Octubre de 2018; Imagen: ( ) Hufftinton Post 


\section{EL CURATOR / EL LÍDER}

A través de la historiografía del arte (de cualquiera de las opciones que el buffet self service académico nos ofrece) se produce, en un orden inmanente de creación del Cosmos, movimientos tectónicos, telúricos y sociohistóricamente engarzados en torno a la idea de 'autoría'. De la obra de arte. Se entiende. Claro. Tras la alegre deriva en la que el conservador jefe de los museos acabó tomando protagonismo en la programación expositiva para devenir en comisario, pronto su figura comenzó a rutilar, hechizar, magnetizar (con o sin razón). William C. Seitz en 1965 con The Responsive Eye, Kynaston McShine en 1966 con Primary Structures -ambos en el MoMA- o Jasia Reichardt con en 1968 con Cybernetic Serendipity en el ICA sentaron los fundamentos de la figura del curator o comisario que, sin movérsele un ápice el peinado ad hoc, oscilaba entre la audacia aristotélica, lo intelectual pop y el mesianismo estético. Pero siempre desde la univocidad.

Su ahora imprescindible función de leader o guía, de lector, de traductor abismal entre la esencia platónica del texto oculto y la forma, le hace aparecer como descifrador vicarial-casi estrella rock- ante esa apariencia externa hermética e insoldable que cada vez más se empecina en lucir el arte contemporáneo. (Como si por ininteligible le fuéramos a respetar más.)

Telégrafo primero y escáner allá por 1840, luego cine, televisión y vídeo convergen en una radical transformación del proceso informacional de comunicación (Claude E. Shannon, 1949) gracias a la "desmaterialización del mensaje", cambiando para siempre las reglas de estos sistemas. Así, tanto el mensaje, como el transmisor, las señales, el canal, el emisor, el receptor y hasta las fuentes de ruido mismas, quedan heridas de muerte ante la potencial evaporación física de los signos.

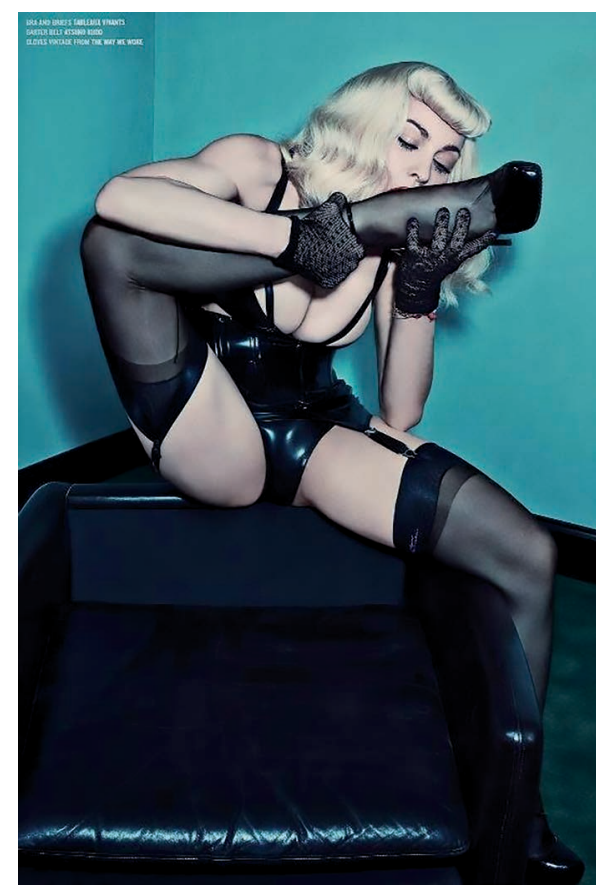

Steven Klein, The Power of Pop (Madonna), V Magazine $n^{\circ} 89$, Nueva York, mayo de 2014; Imagen: () V Magazine 


\section{UNA NUEVA RELACIÓN CON LA OBRA DE ARTE}

La virtual desaparición del soporte tradicional (lienzo, mármol, barco o urinario, tanto da) ofreció la posibilidad de establecer una nueva relación de participación activa del usuario/visitante con la obra. Un espectador que, de un modo feliz e inesperado sin que nadie le pidiera permiso, se convertía en el espacio físico, territorio y soporte material donde habitase el acto de comunicación y, por tanto, la obra de arte. El cuerpo biológico del incauto usuario alojaría a partir de ahora a la obra de arte siendo él su soporte físico, su device final. Al fin, tras tanto esperar, todos seríamos obra de arte.

Allá por los años sesenta los espacios inmersivos (Mark Boyle en el UFO Club de Nueva York, Ken Isaacs con su Knowledge Box, Stan VanderBeek con su Movie Drome, USCO y su Tabernaculum...), prolegómenos del inminente arte interactivo son muestra de un proyecto global que se estaba cocinando donde la nueva autonomía lingüística y mediatizadora del usuario se estableciera desde la equiparación como soporte de un tipo de trabajo colaborativo, abierto, procesual equilibrado e imbricado en la vida. ¡Ja!. El arte para la vida $^{17}$ (vanguardias aquellas geométricas y socialistas); El arte como experiencia(John Dewey 2008); El arte relacional (Nicolas Bourriaud 1998)... Con permiso de Abraham Moles, Max Bense y Tracy Lords ${ }^{18}$.

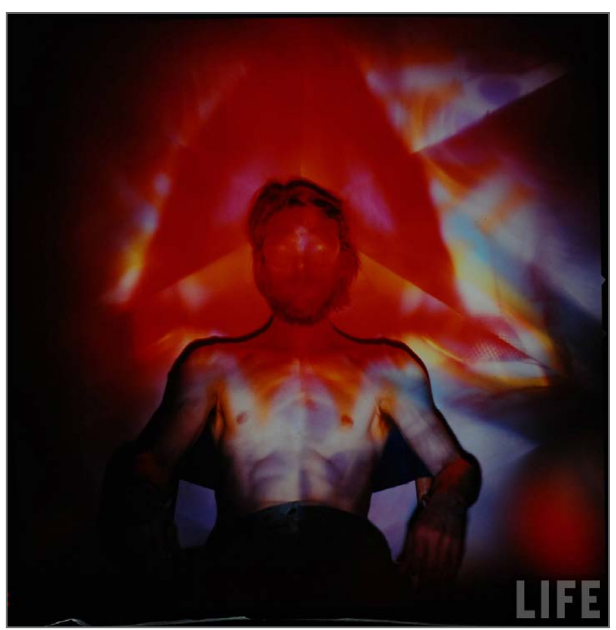

USCO, Tabernaculum perfomance, San Francisco, 1968; Imagen: (C) Revista TIME
Sin embargo el personaje del curator, ávido, poliédrico, (formal a veces, otras chilled, pero siempre al acecho, rapante para no perder su espacio y de negro riguroso, claro) pasa a desplazar y suplantar al usuario mismo (tan ilusionado él con aquello de ser al fin obra de arte -aunque fuera por quince minutos-) en el circuito comunicativo de información. Situándose, simultáneamente, en los espacios funcionales de transmisor, canal, mensaje, emisor y receptor (Shannon \& Weaver 1949). Esto es, constituyéndose en sí mismo como todo un sistema comunicativo de circuito cerrado $^{19}$ y retroalimentado que no necesita de otros elemen- 
tos extra-sistémicos (el usuario o el mundo, siquiera la obra de arte: ésta pasa a ser secundaria en el discurso comisarial) para poder operar y desarrollar su función: decidir qué es arte, cuál es su significado, cuánto su valor. Y atender a la prensa especializada. Cosa importante. Huir siempre de las luces cenitales o directas y de los planos cortos, maquillaje inconfesable pero efectivo, buscar el ángulo de cámara que más nos transforme en una diglosia disciplinaria y mantener una discreta altivez bien merecida. Bien proyectada. En ultra HD o 4K. Según.

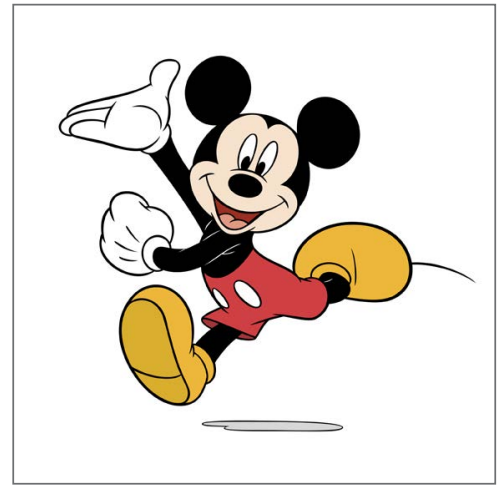

Walt Disney Studios, Mickey Mouse (s/f); Imagen: (C) Disney Corp.

Mickey Mouse y Norbert Wierner mantienen dos monólogos en paralelo. Ni se rozan. Mientras, el comisariado se atornilla fundacional como elemento vertebrador de la obra de arte. Es así como el Sistema Arte despliega toda una narrativa del curator y del crítico de arte como 'transcripción legible' y como 'instalación'.

\section{HACKING THE SYSTEM / OPEN ACCESS}

Como hacker del Sistema Arte he llevado a cabo una acción (llámesele de activismo, performativa o como se quiera) en términos semióticos, simbólicos, lingüísticos, operativos y económicos. Esta es una inversión del artefacto/ dispositivo 'libro' finiquitando la centralidad del texto en el espacio del saber/poder Sistema Arte. Eliminar toda textualidad no sólo atañe a los patrones geomentales de pensamiento (De Kerchhove 1999) (de izquierda a derecha de arriba abajo, en Occidente), sino que resulta una bomba de racimo al empoderamiento del texto sobre la obra de arte. Sirviéndome del bug que resulta de las nuevas tecnologías de impresión digital que permiten tiradas limitadas y costes soportables, he realizado una tirada de cien ejemplares introduciéndome-desde mi irrelevancia y anonimato- entre otras publicaciones del stablishment. Abriendo así la posibilidad de un libre análisis de la obra de arte (y su contexto) y un explicito acuerdo de mutuo respeto entre usuario y obra. Estableciendo así un modelo abierto de cooperación (Himanen 2001, 99), un entorno Open Access para el arte sin intermediarios (Groys 2016, 101). 


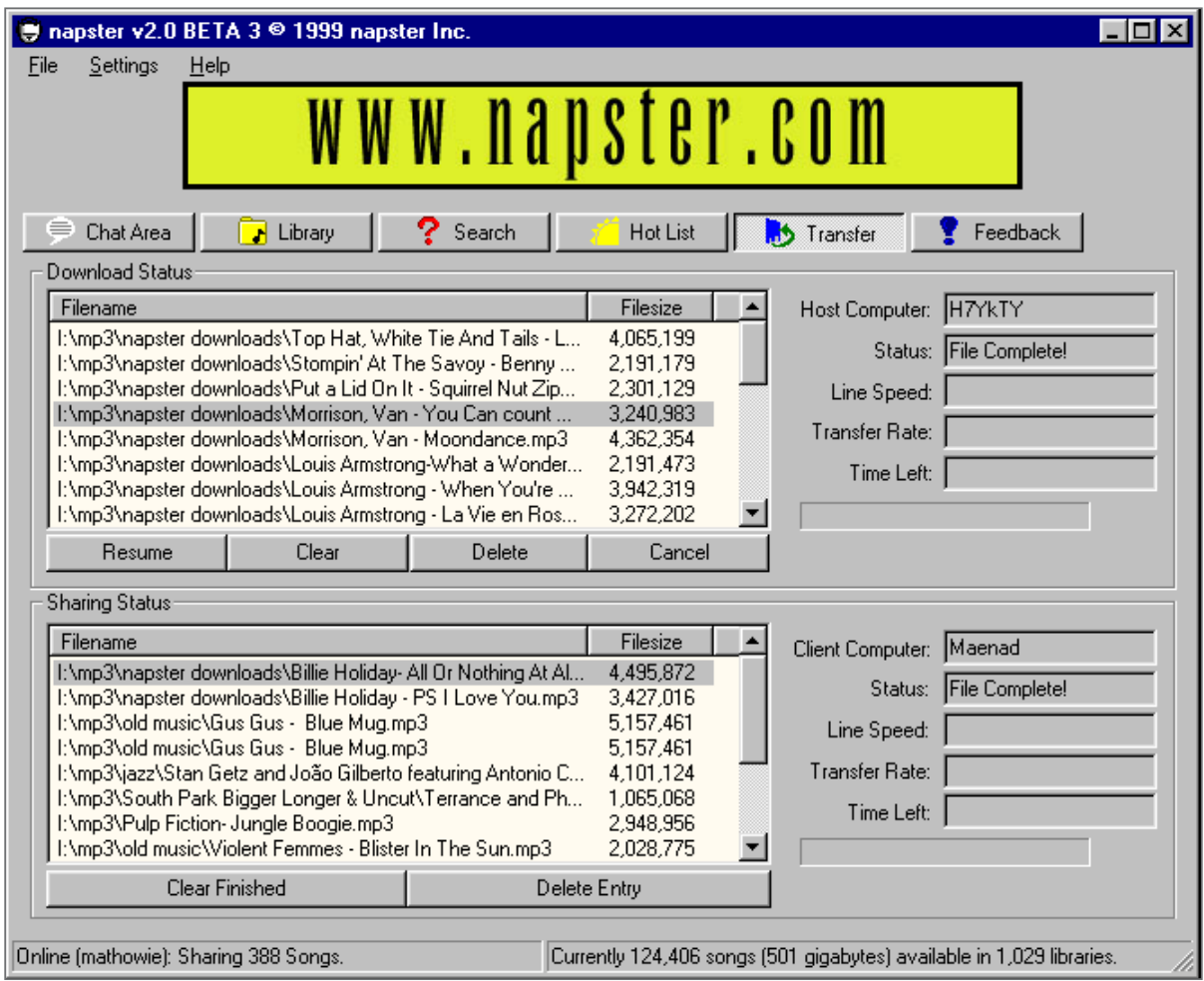

Interface del servidor Napster, 1999 (screeenshot); Imagen: Dominio público

El otro bug por el cual me he infiltrado dentro del Sistema Arte aprovechando su disfunción es la cuestión de los derechos de autor en un mundo que vive en la Sociedad del Acceso con repositorios y webs de contenido infinito y accesible a un solo click. Esto es lo que Peter Suber llama la revolución del acceso (Suber 2013, 1).Contenidos audiovisuales (la materia prima con la que se construye el Sistema Arte)están al alcance de cualquiera en cualquier momento, desde cualquier espacio y con cualquier device. Sin embargo, el Sistema Arte sigue enrocado en planteamientos pre-digitales de acceso restringido, copyrights y entidades de gestión de derechos (en mi trayectoria como editor de libros de arte sé que gran parte del presupuesto de edición va a pagar los derechos de publicación de fotografías de obras en poder de los Museos, pero ese es un dinero que jamás verán los herederos del artista, no nos equivoquemos). No han entendido el poder de esta revolución del contenido audiovisual que es en sí un sistema emergente (Johnson 2003) gracias a los usuarios y sus aportaciones colaborativas a sitios como The Internet 
Archive ${ }^{20}$ y otros repositorios colectivos o sistemas peer to peer (herederos del difunto Napster) como los Torrents.

Para mi acción me he valido de todos estos espacios de intercambio, así como de mi propio archivo de obras audiovisuales que he ido adquiriendo y que luego he compartido en la red con los usuarios. No se ha pagado ningún derecho de uso, comunicación o difusión por estas imágenes, aunque todas ellas están indexadas y reconocidas sus autorías en el libro: 650 imágenes en un trabajo de edición gráfica meticulosa. Del mismo modo que he subvertido la lógica económica y procesual del Sistema Arte, mi trabajo está protegido por una licencia Creative Commons de reconocimiento no derivativa y yo no obtendré beneficio económico alguno. Se trata de difundir y compartir como estrategia de acción colectiva frente a un sistema restrictivo basado en la propiedad y la verticalidad.

\section{HACKING THE SYSTEM / EL LIBRO COMO ARTEFACTO}

Mi acción de hackeo consiste en la edición, publicación, distribución y difusión de un libro de arte, en este caso sobre la desconocida genealogía de la imagen digital ${ }^{21}$. Una obra que desoye la escisión taxonomía del arte/no arte siendo inclusiva de materiales no artísticos, que al prescindir de texto permite la interpretación directa del usuario sin intermediarios y desvinculada del circuito económico pues es gratuita. Una publicación que tiene dos expresiones, por un lado la publicación impresa en papel y distribuida a las bibliotecas públicas de los centros más relevantes del Sistema Arte (MoMA, Centre Pompidou, MNCARS, ZKM...). Esta edición en papel de 100 ejemplares de tirada tiene un coste económico que yo mismo he sufragado. Los ejemplares físicos sólo son donados a entidades públicas de acceso universal donde pueda consultarse o prestarse libremente. Las dimensiones del libro son $21 \times 29$ (A4) y 358 páginas sobre papel $150 \mathrm{~g}$ glossy. Por otro lado, su existencia digital de acceso universal ya que está alojada en el más importante repositorio digital actual que es The Internet Archive (www.archive.org). Desde este mastodóntico servidor se puede consultar o descargar el libro integro en la resolución original de impresión (300pp). Asímismo se encuentra disponible otra versión digital de la obra interactiva e hipervinculada con todas las obras audiovisuales, pero censurada en su contenido pornográfico (www.issu.com). 
Actuamos en soledad, no guiados por ninguna fuerza externa, movidos por la ética, por el reto, por el gusto al juego y a los desplazamientos de sentido. Somos muchos, aunque no nos conocemos, ni sabemos qué hace el otro o por qué motivo. Pero con nuestros silenciosos y aislados patrones de comportamiento estamos estableciendo un verdadero sistema emergente que ya empieza a alcanzar su masa crítica.

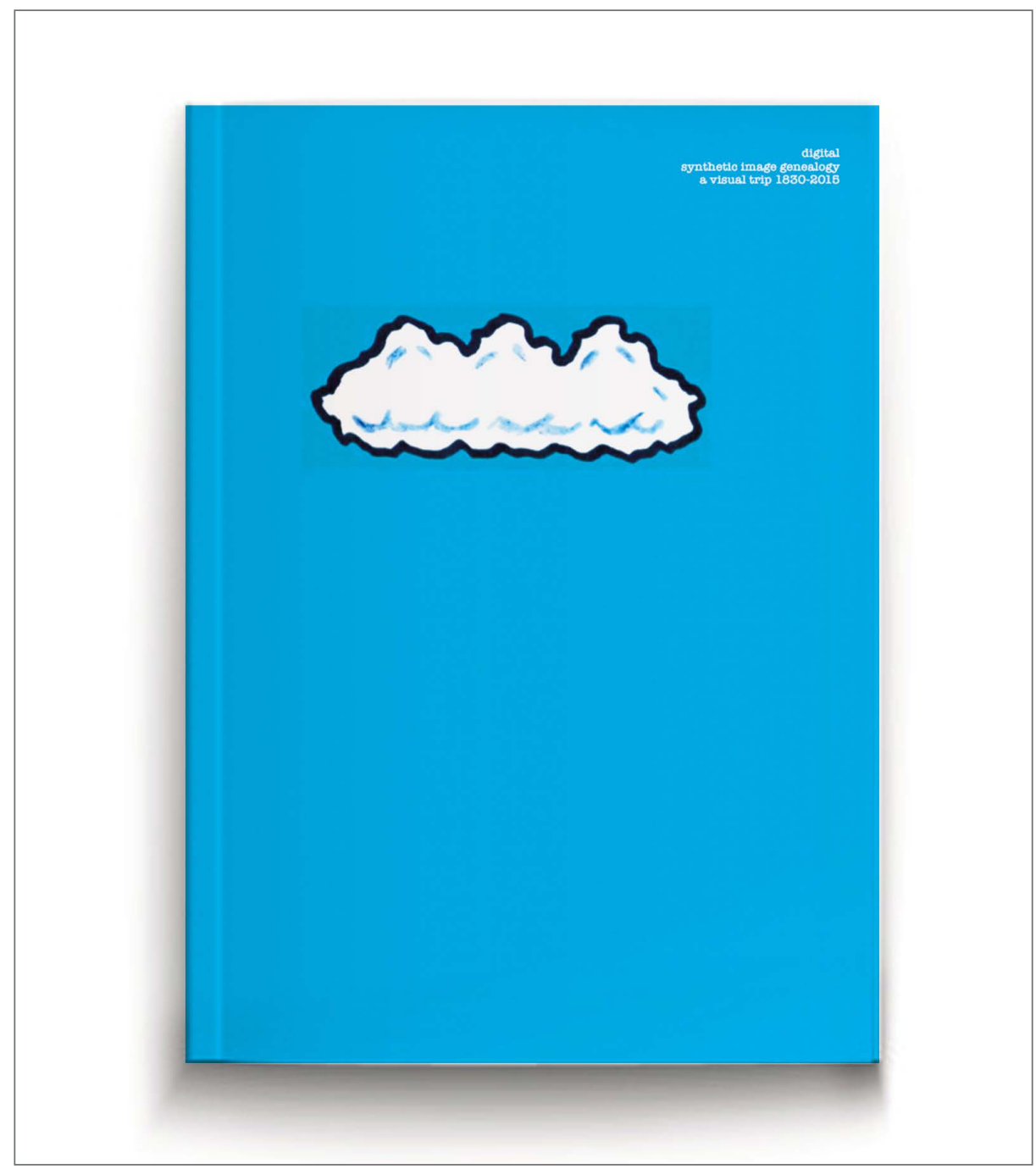

Digital: Synthetic Image Genealogy. A Visual Trip (1830-2015) (San Pedro201822) 


\section{Referencias}

Augé, Marc. (1985) 2010. Los 'no lugares', espacios del anonimato: Una antropología de la sobremodernidad, Traducción, Margarita N. Mizraji, Madrid: Gedisa

Baudrillard, Jean. (1983) 2000. Las estrategias fatales. Traducción de Joaquín Jordá. BarceIona: Anagrama

Baudrillard, Jean. 1979. Cultura y simulacro: La precesión de los simulacros; El efecto Beaubourg; A la sombra de las mayorías silenciosas; El fin de lo social. Traducción, Antoni Vicens, Pedro Rovira. Madrid: Kairos

Bauman, Zygmunt. (2005) 2013. Vida líquida. Traducción de Albino Santos Mosquera. Madrid: Austral

Benjamin, Walter. (1934) 2004. El autor como productor. Traducción y presentación de Bolivar Echeverría. México DF: Itaca

Benjamin, Walter. (1936) 2003. La obra de arte en la época de su reproductibilidad técnica. Traducción de Andrés E. Weikert; introducción de Bolívar Echeverría. México DF: Itaca

Bourriaud, Nicolas. (1998) 2006. Estética relacional. Traducción de Cecilia Beceyro \& Sergio Delgado. Buenos Aires: Adriana Hidalgo

Bunz, Mercedes. 2007. La utopía de la copia: El pop como irritación. Selección y traducción de Cecilia Pavón. Buenos Aires: Interzona

De Kerchhove, Derrick. 1999. La piel de la cultura: Investigando la nueva realidad electrónica. Introducción de Christopher Dewdney; traducción: David Alemán. Barcelona: Gedisa

Dewey, John. (1934) 2008. El arte como experiencia. Traducción y prólogo de Jordi Claramonte. Madrid: Paidós

Foucault, Michel, (1975) 2012. Vigilar y Castigar, Nacimiento de la prisión. Traducción Aurelio Garzón del Camino. Madrid: Siglo XXI

Foucault, Michel (1994) 1999. Estrategias de poder: Obras esenciales, volumen II. Traducción de Fernando Alvarez Uria \& Julia Valera. Buenos Aires: Paidós

Groys, Boris. 2016. Arte en flujo: Ensayos sobre evanescencia del presente. Taducción, Paola Cortes Rocca Buenos Aires: Caja Negra

Himanen, Pekka. 2001. La ética del hacker y el espiritu de la era de la información. Prólogo de Linus Torvalds; epílogo de Manuel Castells; traducción de Ferran Meler Ortí. Barcelona: Destino

Holzwarth, Hans Werner, ed. 2011. Arte moderno 1870-2000: Del Impresionismo a la actualidad. Traducciones, Ambrosio Berasain, Sergio Pawlowsky \& Pablo Álvarez. Köln: Taschen

Johnson, Steven Berlin. 2003. Sistemas emergentes: O qué tienen en común hormigas, neuronas, ciudades y software. Traducción de María Florencia Ferré. Madrid: Turner

Lipovetsky, Gilles \& Jean Serroy. 2015. La estetización del mundo: Vivir en la época del capitalismo artístico. Traducción de Antonio-Prometeo Moya. Barcelona: Anagrama

Lyotard, Jean-Jacques. (1979) 2000. La condición posmoderna: Informe sobre el saber. traducción de Mariano Antolín Rato. Madrid: Cátedra

MacCannell, Dean. (1976) 2017. El turista. Una teoría sobre la nueva clase ociosa. Lucy R. Lippard, col.; Elizabeth Casals, trad. Santa Cruz de Tenerife: Melusina 
Marx, Karl (1867) 1975. 'Los dos factores de la mercancía: valor de uso y valor (sustancia del valor, magnitud del valor)'. En El Capital, tomo I. Madrid: Siglo XXI

Mcintrye, Lee. 2018. Post-Truth. Cambridge MA: MIT

San Pedro Salazar, Abraham. 2018. Digital: Synthetic image genealogy; A visual trip (18302015). Madrid: A libros

Shannon, Claude \& Warren E. Weaver. 1949. The mathematical theory of communication. Chicago: University of Illinois

Sontag, Susan. (1966) 2018. Contra la interpretación y otros ensayos. Traducción de Horacio Vázquez Rial; revisada por Aurelio Major. Madrid: Debolsillo

Suber, Peter. 2013. Open Access. Cambridge MA: MIT

Venturi, Robert, Denise Scott Brown \& Steven Izenour. 1977. Learning from Las Vegas: The forgotten symbolism of architectural form. Cambridge MA: MIT

Virilio, Paul. 1991. ‘Overexposed city’. En The lost dimension. New York: Semiotext(e)

\section{Notas}

${ }^{1}$ Ya lo avanzó Walter Benjamin en la década de los 30 ante el advenimiento de radio y cine.

2 58.405.000 dólares fue la cifra por la que se vendió el Balloon Dog (Orage ) de Jeff Koons el 13 de Noviembre de 2013 en Christie's Nueva York.

${ }^{3}$ Un "bug" un error, un defecto o fallo en el código fuente de los sistemas informáticos. Son los puntos de entrada del hacker que podrá a partir de esta malfunción generar nuevos e inesperados comportamientos y acciones del sistema.

${ }^{4}$ En terminología hacker estas herramientas son los "exploits", software que permite aprovecharse de los errores de programación del Sistema y con los cuales obtener los resultados y comportamientos deseados.

${ }^{5}$ El ejemplo clásico de este fenómeno lo incardina la enciclopedia de 45 volúmenes en su edición en castellano Summa Artis (Espasa Calpe, 1990) pero se puede comprobar en cualquier libro de arte como 'Arte Moderno' (1870-2000), del impresionismo a la actualidad' o en exposiciones como Dadá Ruso 1914-1924 comisariada por Margarita Tupitsyn en el MNCARS de Madrid en 2018.

${ }^{6}$ Obviamente nos referimos a urinario de Marcel Duchamp (1917).

${ }^{7}$ Al parecer, el sentido de la estética, el gusto por la simetría y el reparto de figuras en el espacio son compartidos por humanos y simios superiores (orangutanes, gorilas y chimpancés).

8 "Art Brut" es un término acuñado en 1945 por Jean Dubuffet para referirse al arte creado por gentes ajenas al mundo artístico sin una formación académica, especialmente pacientes psiquiátricos pero también autodidactas, pintores naïfs y grandes simios.

${ }^{9}$ La Galería de los Uffizi ha estrenado este 2018 un logaritmo complejo para gestionar las enormes colas (de más de 2 y 3 horas) que generan los turistas a sus puertas.

${ }^{10} \mathrm{El}$ 'Otro' es 'lo Otro', la alteridad interpuesta de lo desconocido por el cuerpo según Jaques Lacan. 
${ }^{11}$ Así definía el mundo de las apariencias Santo Tomás de Aquino, como algo "engañoso", visión que se extendió por toda la escolástica medieval.

${ }^{12}$ Lara Almarcegui lo hizo en 2013. Lo pagamos todos los contribuyentes del Estado.

${ }^{13}$ Termino introducido por Daniel Bell, John Kenneth Galbraith y el francés Alain Touraine.

${ }^{14}$ https://cordobapedia.wikanda.es/wiki/Equipo_57

${ }^{15}$ Baudrillard (1979) lo dice así: "No se trata ya de imitación ni de reiteración, ni siquiera se trata de parodia, sino de suplantación de lo real por los signos de lo real, es decir, de una operación de disuasión de todo proceso real por su doble operativo, máquina de índole reproductiva, programática, impecable, que ofrece todos los signos de lo real y, en cortocircuito, todas sus peripecias.

${ }^{16}$ Sala Sotheby's, 6 de octubre de 2018.

${ }_{17}$ Proclama de todas las vanguardias del proyecto modernista que reclaman insertar el arte en la vida cotidiana como una experiencia más dándole así poder de acción real sobre la sociedad. Epígono de esta perspectiva es la obra (Benjamin [1934] 2004).

${ }^{18}$ Icono del cine pornográfico de los años ochenta. Legendarios eran sus sonidos guturales, así como su vida ya que todo el porno que rodó bajo la tutela de su madre/productora, lo hizo antes de ser mayor de edad. Al cumplir los dieciocho, dejo el cine para adultos.

19 Un sistema autónomo de comunicación que se puede ver ágilmente se encuentra en la obra Reina (2007), del vasco Javier Ruiz de Infante donde un sistema de videovigilancia dispone de una sola cámara que enfoca al puesto mismo de control.

${ }^{20}$ Internet Archive es una biblioteca digital sin fines de lucro con sede en San Francisco con la misión declarada de "acceso universal a todos los conocimientos". Proporciona acceso público gratuito a colecciones de materiales digitalizados, incluidos sitios web, aplicaciones / juegos de software, Música, películas / videos, imágenes en movimiento y casi tres millones de libros de dominio público. A partir de octubre de 2016, su colección superó los 15 Petabytes.

${ }^{21}$ Disponible para lectura dinámica y descarga en alta resolución en: https://archive.org/details/ DigitallmageGenealogy300PgSueltas/page/n275

${ }^{22}$ Existe también una versión interactiva con acceso directo a las obras audiovisuales (pero censurada en dos páginas por su contenido explícitamente pornográfico) en: https://issuu. com/abrahamsanpedrosalazar/docs/digital_ccensored 